\title{
(9)
}

Antonio M. ${ }^{a}$ Ávila*

\section{LA EVOLUCIÓN DEL SISTEMA DE SOLUCIÓN DE DIFERENCIAS DE LA OMC}

Con este artículo se cierra el análisis de la Organización Mundial de Comercio (OMC) en sus veinte años de funcionamiento que veníamos realizando, y versa sobre el Sistema de Solución de Diferencias (SSD), que es el pivote sobre el que descansa la OMC, y que por un lado ha conseguido una serie de éxitos, pero esos éxitos, e incluso su independencia, han suscitado críticas. Tratemos de entender las razones de ambas cosas.

Palabras claves: paneles, GATT, Organización Mundial de Comercio, derecho internacional, relaciones económicas internacionales.

Clasificación JEL: F13, F14, K33.

\section{Introducción}

A partir de 2017 Miguel Ángel Díaz Mier y yo, de acuerdo con la colaboración que manteníamos desde nuestro primer encuentro profesional, en noviembre de 1982, precisamente para afrontar unas eventuales represalias norteamericanas contra las exportaciones españolas a EE UU, por no formar parte del acuerdo de subvención del GATT, relacionado con la no incorporación a nuestro sistema tributario del IVA, decidimos que en el entorno del vigésimo cumpleaños de la OMC era conveniente dar un repaso al sistema de derecho y al institucional del GATT-OMC, que tan bien venía rigiendo el comercio internacional de productos,

\footnotetext{
* Doctor en Derecho y Doctor en Ciencias Económicas. Versión de septiembre de 2019.

DOI: https:/doi.org/10.32796/bice.2019.3116.6915
}

servicios y propiedad intelectual, especialmente en lo relacionado con las políticas comerciales de los diversos Estados, cuya armonización es, en principio, el objetivo fundamental de este sistema.

En este sentido, publicamos en el Boletín de Información Comercial Española (BICE), en los números 3050 y 3058, «Reflexiones sobre las dos primeras décadas de la OMC I y II»; en el número 3084, el artículo «Reflexiones sobre el Acuerdo ADPIC»; y en el número 3094, el artículo "La evolución de la OMC en la década del 2010».

Los dos pensábamos que este conjunto de estudios debía concluirse con un examen del Sistema de Solución de Diferencias (SSD), que estimamos la piedra angular sobre la que pivota todo el sistema y el funcionamiento de la OMC, y el motivo por el que muchos críticos quieren o aspiran a incorporar otros temas, $D$ 
ajenos, en principio, al comercio y a la agenda de la OMC, con riesgo de convertirla en una institución elefantiásica e inútil.

Ese artículo tardó en escribirse tanto por otros compromisos profesionales como por la enfermedad y posterior fallecimiento del profesor Díaz Mier, a quien quiero dedicar estas reflexiones.

\section{Antecedentes}

Cuando se firmó el Acuerdo de Aranceles y Comercio, GATT, en sus siglas en inglés, - debemos recordar que su nacimiento se debe a que el Senado de EE UU vetaba la creación de una Organización Internacional de Comercio (OIC) - era, fundamentalmente, la Parte IV del Proyecto de Tratado de la OIC o Carta de la Habana, y en ese capítulo no estaba previsto ningún sistema de solución de diferencias, tanto por el carácter de estricta provisionalidad con la que se inició el GATT —a la espera de la aprobación de la OIC_- como por el carácter original no institucional del propio acuerdo.

La paulatina consolidación del GATT y la aparición inevitable de desencuentros y conflictos comerciales obligaron, desde el primer día, a la pequeña burocracia del acuerdo, a ingeniarse algún método de solución, y lo encontraron en los grupos de trabajo o paneles, primero, compuestos solo de expertos de los países contendientes, y, segundo, ante la proliferación de consultas entremezcladas con varias partes, empezaron a aparecer a petición de la Secretaría expertos neutrales en los conflictos, a partir de una interpretación inteligente de los artículos xxII y xxIII del GATT. Estos expertos no podían ser nacionales de ninguno de los países contendientes.
Como señalaba el profesor Díaz Mier (1983) en su tesis doctoral: «El mecanismo de solución de diferencias del GATT es el resultado de un largo proceso de interpretación práctica de los artículos claves, el XXII y el XxIII, y se basa en la idea-fuerza de conseguir la conciliación entre las partes en un conflicto antes de utilizar otros tipos de procedimientos».

No se trata ahora de historiar todo el proceso y la consolidación de los famosos paneles a partir de la única obligación que fija el artículo XXIII, y es tan simple, como señala el profesor Jackson, como que las partes ante cualquier problema deben consultar (Jackson, 1969). A partir de este pequeño mimbre se fue desarrollando un sistema relativamente eficaz, pero que en los años de negociación de la Ronda Uruguay suscitaba críticas que podemos sintetizar en las siguientes características: fragmentación del sistema (cada acuerdo de la Ronda Tokio incorporaba un sistema propio análogo pero independiente), falta de unidad de criterio de los diversos paneles, lentitud en los trámites, falta de institucionalización y escasa utilización (Ávila y Díaz Mier, 1994).

Por eso, desde el principio, en las negociaciones de la Ronda Uruguay se dedicó un apartado de las negociaciones al tema de la solución de diferencias para reformarlo, conservando lo esencial del GATT y eliminando los defectos, de tal manera que en el acta final en la que se incorporaron los resultados de la Ronda Uruguay de Negociaciones Comerciales multilaterales se incluyó «la creación de un mecanismo de solución de diferencias obligatorio e integrado al que se dota de automaticidad en la toma de decisiones». Como Pablo Zapatero (2003) señala, «este mecanismo carece de precedentes en la historia institucional del Derecho Internacional. Es el guardián del Derecho de la OMC». De la misma opinión lo calificó el gran experto en $\triangleright$ 
GATT y OMC, el profesor Jackson, para el que es un sistema único, un gran logro, aunque, como veremos después, puede, de hecho, ser el Tribunal de Derecho Internacional más importante y poderoso (Jackson, 2009).

Vamos a describir, brevemente, el sistema en los mismos términos esquemáticos en los que lo hace el propio organismo, indicando que hay tres fases: consulta bilateral, constitución del panel y eventual apelación, como si se tratara de un órgano judicial que apela a una institución superior unificadora, el Órgano de Apelación (OA).

El esquema es el mismo que utilizamos en nuestra obra Regulación del comercio internacional tras la Ronda Uruguay.

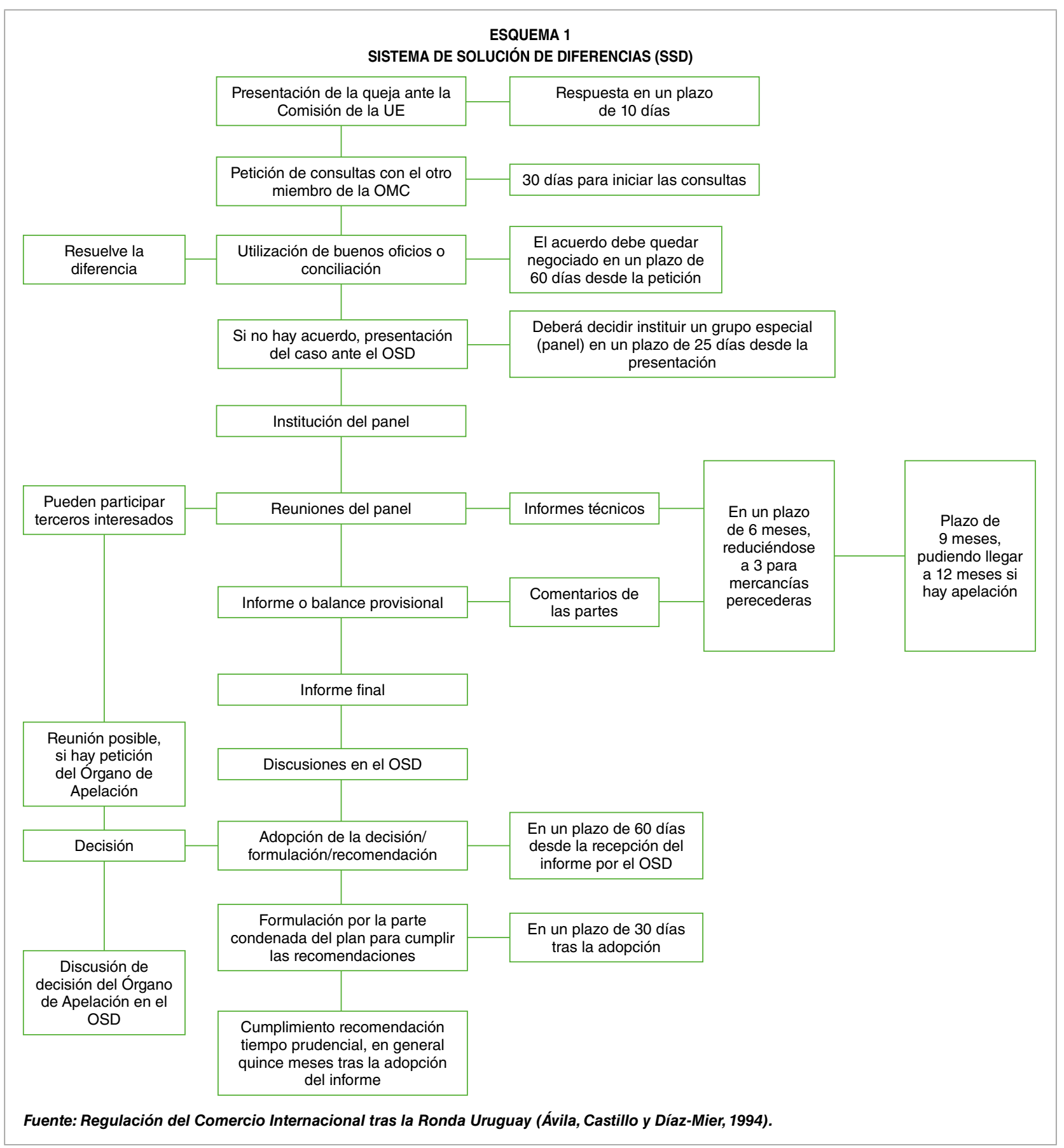


CUADRO 1

NÚMERO DE INFORMES ADOPTADOS DEL ÓRGANO DE APELACIÓN: 1995-2014

\begin{tabular}{|c|c|c|c|}
\hline Año & $\begin{array}{c}\text { Anuncios de apelación } \\
\text { presentados }\end{array}$ & $\begin{array}{c}\text { Apelaciones en procedimientos } \\
\text { iniciales }\end{array}$ & $\begin{array}{c}\text { Apelaciones en procedimientos } \\
\text { artículos }\end{array}$ \\
\hline 1995 & 0 & 0 & 0 \\
1996 & 4 & 4 & 0 \\
1997 & 6 & 6 & 0 \\
1998 & 8 & 8 & 0 \\
1999 & 9 & 9 & 0 \\
2000 & 13 & 11 & 2 \\
2001 & 9 & 5 & 4 \\
2002 & 7 & 6 & 1 \\
2003 & 6 & 5 & 1 \\
2004 & 5 & 5 & 0 \\
2005 & 10 & 8 & 2 \\
2006 & 5 & 3 & 2 \\
2007 & 4 & 2 & 2 \\
2008 & 13 & 10 & 3 \\
2009 & 3 & 1 & 2 \\
2010 & 3 & 3 & 0 \\
2011 & 9 & 9 & 0 \\
2012 & 5 & 5 & 0 \\
2013 & 1 & 1 & 0 \\
2014 & 9 & 8 & 1 \\
\hline Total & 129 & $\mathbf{1 0 9}$ & \\
\hline Fuente: Organización Mundial de Comercio. & & 20 \\
\hline
\end{tabular}

Lo cierto es que, como señaló en su día Montaña (1997), el SSD tuvo un inicio espectacular, más de sesenta reclamaciones durante los dos primeros años.

En el Cuadro 1 se establece el número de informes adoptados por el OA, 1995-2014, y en el Cuadro 2, el porcentaje de informes de grupos especiales que han sido apelados al OA. A partir de los datos de la OMC he hecho un cuadro distribuyendo los paneles entre los grandes acuerdos de la OMC, mercancías, servicios, propiedad intelectual, solución de diferencias y los acuerdos plurilaterales y otros (Cuadro 3), del que se deduce que absolutamente todos los textos de Tratado de Marrakech han sido interpretados en el SSD, una muestra más de su éxito.

También puede ser interesante examinar quiénes son los principales demandantes y demandados; curiosamente, EE UU y la Unión Europea, con diferencia, son los principales demandantes.

Ahora bien, para entender la actual situación de un sistema cuya naturaleza jurídica es más difícil de determinar porque viene de un sistema de prueba y error y pura experiencia, como el profesor Jackson señaló, y que tiene una doble vertiente (jurídica, pero también inevitablemente política), debemos ver sus características.

\section{Características del sistema}

\subsection{Subjetivismo y derecho supletorio}

Lo primero que debemos tener claro es que el SSD está dotado de un fuerte subjetivismo, en cuanto que solo las partes pueden $\triangle$ 
CUADRO 2

PORCENTAJE DE INFORMES DE GRUPOS ESPECIALES QUE HAN SIDO APELADOS: 1995-2014 (a)

\begin{tabular}{|c|c|c|c|c|c|c|}
\hline \multirow[b]{2}{*}{$\begin{array}{l}\text { Año de } \\
\text { adopción }\end{array}$} & \multicolumn{2}{|c|}{$\begin{array}{c}\text { Todos los informes de grupos } \\
\text { especiales }\end{array}$} & \multicolumn{4}{|c|}{$\begin{array}{l}\text { Informes de grupos especiales distintos de los establecidos de } \\
\text { conformidad con el párrafo } 5 \text { del artículo } 21 \text { del ESD (b) }\end{array}$} \\
\hline & $\begin{array}{l}\text { Informes de } \\
\text { grupos } \\
\text { especiales } \\
\text { adoptados (c) }\end{array}$ & $\begin{array}{l}\text { Informes de } \\
\text { grupos } \\
\text { especiales } \\
\text { apelados (d) }\end{array}$ & $\begin{array}{c}\text { Porcentaje de } \\
\text { informes de } \\
\text { grupos especiales } \\
\text { apelados }\end{array}$ & $\begin{array}{l}\text { Informes de } \\
\text { grupos } \\
\text { especiales } \\
\text { adoptados }\end{array}$ & $\begin{array}{l}\text { Informes de } \\
\text { grupos } \\
\text { especiales } \\
\text { apelados }\end{array}$ & $\begin{array}{c}\text { Porcentaje de } \\
\text { informes de } \\
\text { grupos especiales } \\
\text { apelados }\end{array}$ \\
\hline 1996 & 2 & 2 & 100 & 2 & 2 & 100 \\
\hline 1997 & 5 & 5 & 100 & 5 & 5 & 100 \\
\hline 1998 & 12 & 9 & 75 & 12 & 9 & 75 \\
\hline 1999 & 10 & 7 & 70 & 9 & 7 & 78 \\
\hline 2000 & 19 & 11 & 58 & 15 & 9 & 60 \\
\hline 2001 & 17 & 12 & 71 & 13 & 9 & 69 \\
\hline 2002 & 12 & 6 & 50 & 11 & 5 & 45 \\
\hline 2003 & 10 & 7 & 70 & 8 & 5 & 63 \\
\hline 2004 & 8 & 6 & 75 & 8 & 6 & 75 \\
\hline 2005 & 20 & 12 & 60 & 17 & 11 & 65 \\
\hline 2006 & 7 & 6 & 86 & 4 & 3 & 75 \\
\hline 2007 & 10 & 5 & 50 & 6 & 3 & 50 \\
\hline 2008 & 11 & 9 & 82 & 8 & 6 & 75 \\
\hline 2009 & 8 & 6 & 75 & 6 & 4 & 67 \\
\hline 2010 & 5 & 2 & 40 & 5 & 2 & 40 \\
\hline 2011 & 5 & 5 & 63 & 8 & 5 & 63 \\
\hline 2012 & 18 & 11 & 61 & 18 & 11 & 61 \\
\hline 2013 & 4 & 2 & 50 & 4 & 2 & 50 \\
\hline 2014 & 15 & 13 & 87 & 13 & 11 & 85 \\
\hline Total & 201 & 136 & 172 & 172 & 115 & 67 \\
\hline \multicolumn{7}{|c|}{ (a) En 1995 no se adoptaron informes de grupos especiales. } \\
\hline \multicolumn{7}{|c|}{$\begin{array}{l}\text { (b) De conformidad con el párrafo } 5 \text { del artículo } 21 \text { del ESD, se podrá establecer un grupo especial para entender de un "desacuerdo en cuanto a la } \\
\text { existencia de medidas destinadas a cumplir las recomendaciones y resoluciones [del OSD] o a la compatibilidad de dichas medidas con un acuerdo } \\
\text { abarcado" después de la adopción de un informe anterior de un grupo especial o del Órgano de Apelación. }\end{array}$} \\
\hline \multicolumn{7}{|c|}{$\begin{array}{l}\text { (c) Los informes del Grupo Especial que se ocupó de los asuntos CE - Banano III (Ecuador), CE - Banano III (Guatemala y Honduras), CE - Banano } \\
\text { III (México) y CE - Banano III (Estados Unidos) se contabilizan como un solo informe. Los informes de los grupos especiales que se ocuparon de los } \\
\text { asuntos: Estados Unidos - Salvaguardia sobre el acero, CE - Subvenciones a la exportación de azúcar y CE - Trozos de pollo, también se contabilizan } \\
\text { como un solo informe en cada una de esas diferencias. }\end{array}$} \\
\hline \multicolumn{7}{|c|}{$\begin{array}{l}\text { (d) Los informes de grupos especiales se contabilizan como informes que han sido objeto de apelación cuando han sido adoptados según han sido con- } \\
\text { firmados, modificados o revocados por un informe del Órgano de Apelación. El número de informes de grupos especiales puede ser distinto del número } \\
\text { de informes del Órgano de Apelación porque algunos informes del Órgano de Apelación examinan más de un informe de grupo especial. }\end{array}$} \\
\hline \multicolumn{7}{|c|}{ Fuente: Organización Mundial de Comercio. } \\
\hline
\end{tabular}

ponerlo en marcha y solo ellas — reclamantes y demandantes - pueden paralizarlo, llegando a un acuerdo amistoso en cualquier momento del procedimiento. De alguna manera se pretende que un conflicto comercial, que en principio es político, se pueda, paulatinamente, y como si no se quisiera, juridificar —nunca hay que olvidar que la OMC es una institución básicamente jurídica, con un derecho propio-. Esto quiere decir que el procedimiento es claramente supletorio. Solo si no hay acuerdo y las partes lo quieren se pone en marcha, y solo ellos pueden finalizar el desacuerdo antes de dictar resolución.

\subsection{Flexibilidad}

EI SSD se beneficia con una exclusividad, pero al mismo tiempo contiene múltiples $\triangle$ 
CUADRO 3

SOLUCIÓN DE DIFERENCIAS POR MATERIAS

\begin{tabular}{|l|r|}
\hline Acuerdos de mercancías & Número \\
\hline Agricultura & 84 \\
Antidumping & 132 \\
Valoración en aduanas & 17 \\
GATT 47 & 1 \\
GATT 1994 & 482 \\
Licencias de importación & 48 \\
Inspección previa a la exportación & 4 \\
Normas de origen & 7 \\
Salvaguardia & 61 \\
Medidas sanitarias y fitosanitarias & 48 \\
Subvenciones & 127 \\
Otros & 54 \\
Textiles & 16 \\
Inversión relacionada con el comercio & 44 \\
Facilitación de comercio & 1 \\
\hline Acuerdos de servicios & 29 \\
TRIPS & 41 \\
SSD & 19 \\
ACP Modificado & 0 \\
Protocolo de adhesión & 36 \\
\hline Acuerdos plurilaterales & \\
\hline Contratación pública & 4 \\
Aeronaves & 0 \\
Bovino & 0 \\
Lácteos & 0 \\
\hline Fuente: elaboración propia a partir de datos de la OMC. & \\
\hline
\end{tabular}

modos de resolución que pueden ser utilizados alternativamente, simultanea o sucesivamente, ya que el lugar del acuerdo amistoso está adquirido desde el principio (Sorel, op.cit.).

\subsection{Búsqueda de equilibrio}

Lo que intenta el sistema es evitar el juego de represalias y excluir las medidas unilaterales, y que se pueda acudir a otras instancias ajenas a la propia OMC. Eso quiere decir que por el sistema de SSD no buscan ningún principio abstracto de equidad o justicia, simplemente trata de restablecer el equilibrio que alguna parte ha roto, y, por tanto, deshacer el daño causado (si es que se demuestra que se ha causado daño).

\subsection{Juridificación creciente}

Otra característica es la juridificación creciente: «El lugar del derecho se acrecienta a medida que avanza el procedimiento, en la medida en que se trata de una función esencial y delicada; el OA incita fuertemente a los grupos especiales a implementar una metodología muy estructurada que se arraiga en el derecho general» (Sorel, op.cit.) fundamentado en el artículo 3-2 del memorándum; aunque no queremos examinar con detenimiento ningún caso concreto, sí queremos citar el de bebidas alcohólicas ${ }^{1}$; los principios de interpretación que mencionan son los típicos del derecho: sentido ordinario de los términos del tratado, leído ese importante panel en su contexto, objetivo y fin, e incluso el principio de efectividad, porque deja claro los criterios de interpretación jurídica que se deben utilizar.

\subsection{Sistema democrático}

Uno de los principios jurídicos en que se fundamenta la OMC es el de «no discriminación", instrumentado a través de la cláusula de nación más favorecida en sentido multilateral e incondicional, y el principio del trato nacional que obliga a negociaciones comerciales casi permanentes, por tanto a intercambios y concesiones. EI SSD, si se pone en marcha, tiene como objetivo, precisamente, restablecer ese equilibro. Ese es el único objetivo del SSD.

Ello a través de una solución amistosa de diferencias con amplia participación de los contendientes (la participación sería otro rasgo altamente positivo del sistema). Pero el $\triangleright$

DS510/11 -WT/DS11-8. Informe de apelación 4-X-1996 y adoptado definitivamente por el OA, 1-XI-1996. 
sistema, a través de este procedimiento participado y dialogado, trata de buscar soluciones eficaces que refuercen la seguridad y previsibilidad del sistema, rellenando las inevitables lagunas jurídicas, y, de esta manera, cumplir los objetivos fundacionales, sobre todo intentando encontrar un mecanismo de balance de beneficios, equilibrando los daños y en la medida de lo posible amparando a otras partes más débiles.

Todas estas características se han concretado, como muestran las estadísticas, en el único mecanismo efectivo en la sociedad internacional para resolver conflictos y además con posibilidad de establecer sanciones comerciales.

Como señala Zapatero (2003), en uno de los más interesantes trabajos sobre las implicaciones jurídicas y cuasiconstitucionales del SSD, «algunos autores llegan, por todo ello, a calificar el SSD como la "joya de la corona de la OMC" o incluso como los dientes de la OMC. El SSD no es un mero tema de moda y constituye un fenómeno jurídico que, a caballo del proceso de internacionalización de la economía, tendrá cada vez más implicaciones para nuestras sociedades, pero también para la sociedad internacional y el derecho internacional en su conjunto».

\subsection{Unidad e integridad del sistema}

EI SSD se caracteriza también por la unidad e integridad del sistema en cuanto que en ningún caso está previsto recurrir al Tribunal Internacional de Justicia (el Fondo Monetario Internacional tiene esa cláusula, aunque no se utilice nunca) y aunque el artículo 3.2. del entendimiento señala literalmente «que el SSD sirve para preservar derechos y obligaciones de los miembros en el marco de los acuerdos abarcados y para aclarar las disposiciones vigentes de dichos acuerdos, de conformidad con las normas usuales de interpretación del derecho internacional público». Aunque sí se abre el OA a aplicar las reglas y costumbres del derecho internacional, y éstas han sido tenidas en cuenta por los diversos paneles, el $\mathrm{OA}$ ha procurado siempre atenerse al propio derecho sin utilizar otras fuentes, solo las reglas de interpretación.

La reforma del 2003 (WT-AB-VP12) mejora el sistema, disciplinando la participación de terceras partes en un panel, legalizando la presencia del observador pasivo, esto es, la parte que no ha presentado escrito en los plazos establecidos.

El profesor Jackson, en su obra citada, señala que «en líneas generales los observadores sugieren que el cumplimiento de los informes finales del Órgano de SSD han sido bastante buenos, pero en años recientes ha habido una serie de casos famosos que en su mayoría culminan en decisiones contrarias a EE UU o a la Unión Europea, cuyo cumplimiento no ha sido adecuado, ofreciendo así un trasfondo problemático al problema general del cumplimiento» (Jackson, 2009). En la misma línea de valoración positiva se mueven otros autores (Sorel, 2004) o los clásicos Carreau y Juillard.

\section{Estados Unidos y la OMC, y sus soluciones de diferencias}

No hay la menor duda sobre el carácter hegemónico de EE UU en el mundo del siglo xx y XXI, sobre todo tras la Segunda Guerra Mundial, y, por tanto, el papel relevante que ha jugado y juega en el establecimiento de un orden jurídico-económico internacional. 
Al principio señalábamos cómo la oposición del Senado de EE UU, —el órgano competente en su Constitución-, para autorizar la firma de tratados internacionales, provocó que la Carta de La Habana que creaba la OIC no entrara en vigor nunca y que como alternativa se lanzara el Acuerdo General de Aranceles y Comercio, que como acuerdo sí puede firmar el Poder Ejecutivo, el presidente, aunque lógicamente tiene en su derecho interno un inferior rango jerárquico que los tratados internacionales, y ese era el gran problema que tenía el viejo GATT, su estatuto jurídico inferior y los consiguientes efectos en la aplicabilidad en el ámbito interno del derecho.

También es sabido el papel que jugó EE UU en el establecimiento del orden económico de posguerra; por citar un clásico, los trabajos de Gardner (1994) o, más recientemente, Stell (2014), pero en cambio es más desconocida la fuerte batalla interna en EE UU que se estableció para vencer las tradicionales fuerzas internas contrarias a los mercados abiertos, fundamentadas en su fuerte aislacionismo y fuerte excepcionalismo (Caicedo, 2012), aunque quizá sean más explicativas del activismo de EE UU en el orden de posguerra, las obras de Panich y Gindin (2015) o de Gowan (2000), que abarcan la expansión del comercio tras la Segunda Guerra Mundial.

Este aspecto peculiar de la política y la sociedad estadounidense se manifestó también en las negociaciones de la Ronda Uruguay, en la que no estaba previsto inicialmente la creación de una organización de comercio, idea lanzada por Francia para hacer embarrancar las negociaciones de la Ronda Uruguay y para que no se aprobaran con el fin de evitar la firma de un acuerdo de agricultura. Pero los norteamericanos, conscientes de lo que ganaban con la globalización, aceptaron el reto y solo mostraron una honda preocupación por el establecimiento de un SSD y un OA cuyas decisiones eran susceptibles de entenderse que podían ir contra el Congreso norteamericano.

Aunque el Tratado de Marrakech se aprobó con el procedimiento del fast track, rápidamente en apenas dos días de debate, la discusión sí mostró preocupación, como decimos, por algunos temas, especialmente la creación del OA, de tal manera que la Ronda Uruguay se aprobó; pero en EE UU se creó una Corte de Justicia, compuesta de cinco jueces, con la función de examinar las decisiones del OA para ver si eran equitativas o no, y en ese último caso retirarse de la OMC. La Corte tenía una vigencia de cuatro años y su informe fue positivo, como tenían previsto; por tanto, no hubo retirada de la OMC.

Pero desde el principio hubo resquemor en EE UU, algo en principio lógico, porque el nuevo SSD de la OMC era en el derecho internacional algo radicalmente novedoso y planteaba, como muy bien ha estudiado Pablo Zapatero, importantes problemas tanto en lo que se refiere a la norma aplicable a las reglas de interpretación como a la compatibilidad con otros acuerdos internacionales, aunque con una vis atractiva, muy fuerte en el caso de la OMC, que la convierte además en un derecho en permanente regulación.

Quizá sea interesante entender por qué es tan novedoso el SSD de la OMC en el ámbito específico del derecho internacional económico y en general en el ámbito del derecho internacional.

Para ello, debemos recordar que el principio general ha sido la negociación política, teniendo en cuenta los principios generales del derecho y las peculiaridades, reglas y costumbres del derecho internacional, pero lo que no existía, más allá del Tribunal Internacional de Justicia, es un órgano especializado en un $\triangleright$ 
tratado con presencia de terceros, los expertos que forman parte del panel y que no pueden ser nacionales de las partes litigantes. Mientras que la resolución de esos expertos, para hacerse efectiva, necesitaba de la aprobación de las partes litigantes, el sistema no se apartaba de las tradiciones de las negociaciones políticas, digamos, con una intervención externa técnica.

Pero la formalización de un procedimiento subsidiario, subjetivo, suspendible en cualquier momento si las partes lo desean, pero formalizado y más juridificado, y en el que el peso jurídico se acrecienta a medida que el proceso avanza y termina en una acción de apelación cuyas conclusiones y resoluciones finales de ser adoptadas son obligatorias, es un cambio cualitativo y sustantivo radical; es el inicio del triunfo del derecho sobre la pura política y ahí es donde empiezan los problemas y originan tensiones, sobre todo cuando a los poderosos no le dan la razón o no se la dan de manera clara y contundente.

Es, sobre todo, la aparición del OA lo que, a mi juicio, trastoca las tradiciones políticas y es lo novedoso, en cuanto que ese «principio» de progresiva juridificación, que a la larga da estabilidad y seguridad a las relaciones comerciales, equilibra el de la llamada permanente negociación que está en el origen del sistema, aunque los siete miembros del OA, con mandato de cuatro años renovables, sean personas de reconocido prestigio y competencia acreditada en comercio y que conservan prácticas del anterior sistema del GATT, y constituye un «filtro» jurídico que inevitablemente frente a la fragmentación del GATT 1947 permite una jurisprudencia sistematizada y la posibilidad, junto a la perseveración, de la coerción.

Otro problema: las normas aplicables en los principios son todas las de la OMC, porque la operatividad práctica de las fuentes del derecho internacional dentro del SSD se ve influida o afectada por el modelo de norma aplicable que se le ha asignado, esto es, se han hecho sin referencia alguna al derecho internacional, que hasta ahora nunca se preocupó ni poco ni mucho del sistema de paneles, pero ahora nos encontramos con una doble dinámica, la preocupación del derecho internacional sobre el SSD y la apertura del SSD al propio derecho internacional; la tendencia, a mi juicio, es usar las normas de interpretación del derecho internacional y las costumbres, pero teniendo en cuenta exclusivamente los textos de la OMC, aunque, a veces, con la vista puesta en esos tratados, sean regionales, medioambientales o de cualquier naturaleza, para evitar conflictos.

\section{Conclusión}

En resumen, la fuerte institucionalización del SSD a través del OA establece un sistema de consenso negativo (no el positivo que existía con anterioridad en el GATT); además, a EE UU le disgusta que una parte grande de decisiones del OA se dicten fuera del plazo establecido y los jueces del OA se prorroguen en el tiempo, y, por ello, EE UU considera que no son legales sus decisiones, aunque bloquea muchas veces los renombramientos por considerar que los paneles dictados por jueces a los que se les ha caducado su nombramiento son jurídicamente no válidos.

También le parecen excesivas, por no jurídicas, muchas opiniones de los jueces, quizá imbuidos de un carácter constitucional que no tienen ni en letra ni en espíritu los tratados. Y, por último, consideran una mala práctica que el $\mathrm{OA}$ utilice para resolver un asunto precedente, algo paradójico dada la naturaleza jurídica del $\triangleright$ 
ordenamiento jurídico norteamericano de la familia del common law, basado precisamente en el precedente.

Quizá los jueces del OA se olviden de que gran parte el éxito del GATT fue haber sido un «organismo» modesto, y ahora, con la novedad del sistema, no ha asumido esa modestia.

Nos encontramos con una situación paradójica: EE UU es el país que más casos promueve en el OSD, más de 230, muy alejado de la Unión Europea, que es el segundo, y a la par se muestra sumamente crítico. Lo único real es que hay un problema, ya que gran parte del éxito del SSD, desde el GATT, se fundamentó en ser cómodo para los miembros y que los temas se resolvían con deliberaciones, discusiones y consenso; quizá sea necesario volver a ello y plantear reformas que contente a todos. En este sentido, la Unión Europea, en 2018, lanzó propuestas tendentes a flexibilizar sistemas, pero manteniendo la independencia del órgano; asimismo, el presidente del Consejo General ha realizado propuestas en la misma línea.

De las críticas norteamericanas solo son asumibles la falta de consenso. Los órganos tienen que pervivir en el tiempo con o sin nombramiento y los obiter dictum no son lo relevante, sino la resolución en sí misma, y los precedentes es una técnica más que aceptable en derecho; la única crítica es cómo resolver el consenso.

Los tiempos del unilateralismo, populismo, esto es, la falta de rigor en que vivimos, aconsejan mantenerse firme en la defensa de un sistema abierto con instituciones y organismos que, como la OMC, han conseguido éxitos fulminantes y han logrado prosperidad económica para muchos habitantes del planeta, y si hay problemas, debemos buscar flexibilidad y acuerdos, pero no marginar lo que se ha construido. Pongámonos de acuerdo en los plazos de renovación de los miembros del OA y busquemos soluciones a las eventuales extralimitaciones en la línea de la flexibilidad del propio sistema.

\section{Bibliografía}

Ávila, A. M., y Díaz-Mier, M. Á. (2017). Reflexiones sobre el Acuerdo ADPIC. Boletín de Información Comercial Española, 3084, 19-30.

Ávila, A. M., y Díaz-Mier, M. Á. (2017). La evolución de la OMC en la década del 2010. Boletín de Información Comercial Española, 3094, 13-24.

Ávila, A. M., y Díaz-Mier, M. Á. (2014). Reflexiones sobre las dos primeras décadas de la OMC. Boletín de Información Comercial Española, 3050, 13-24.

Ávila, A. M., y Díaz-Mier, M. Á. (2014). Reflexiones sobre las dos primeras décadas de la OMC (II). Boletín de Información Comercial Española, 3058, 27-36.

Ávila, A. M., Castillo, J.A., y Díaz-Mier, M. Á. (1994). Regulación del comercio internacional tras la ronda Uruguay, 230-239. Tecnos.

Caicedo Castillo, A. (2012). El New deal del comercio global. Génesis ideológica del ordenamiento económico de la postguerra. Unidad Editorial.

Carreau, D., y Juillard, P. (2013). Droit International Economique.

Diaz-Mier, M. Á. (1983). Tesis: La solución de diferencias comerciales en las organizaciones internacionales: el caso español. Facultad Ciencias Económicas y Empresariales. Universidad Complutense de Madrid.

Gardner, R. et al. (1994). La diplomacia del dólar y la esterlina. Orígenes y futuro del sistema de Bretton Woods GATT. Galaxia Gutenber.

Gowan, P. (2000). La apuesta por la globalización. La geoeconomía y la geopolítica del Imperialismo euro-estadounidense. Ediciones Akal. 


\section{LA EVOLUCIÓN DEL SISTEMA DE SOLUCIÓN DE DIFERENCIAS DE LA OMC}

Jackson, J. (1969). World trade and the law of Gat. A legal analysis of the general agreement on tariffs and trade. Indianápolis: Bobbs Marrill Company.

Jackson, J. (2009). La OMC y los fundamentos cambiantes del derecho internacional». Págs. 204-205. Marcial Pons.

Montaña, M. (1997). La OMC y el reforzamiento del sistema GATT. McGraw-Hill.

Panitch, L., y Gindin, S. (2015). La construcción del capitalismo global. La economía del imperio estadounidense. Ediciones Akal.
Sorel, J. M. (2004). Resolución de litigios en la OMC. Ciudad Argentina.

Stell, B. (2014). The battle of Bretton Words. Princenton.

World Trade Organization (2018). Gatt Disputes: 1948-1995 (Diferencias planteadas en el marco del GATT). Volúmenes 1 y 2.

World Trade Organization (2017). Manual sobre el Sistema de solución de diferencias de la OCM, 2. ${ }^{a}$ edición.

Zapatero, P. (2003). Derecho del comercio global. Madrid: Thompson Civitas. 